\title{
Diurnal patterns of grazing behavior and humoral factors in supplemented dairy cows
}

\author{
A. J. Sheahan, ${ }^{* 1}$ R. C. Boston,, and J. R. Roche ${ }^{*}$ \\ *DairyNZ, Private Bag 3221, Hamilton 3240, Hamilton, New Zealand \\ †Department of Clinical Studies, New Bolton Center, University of Pennsylvania, Philadelphia 19104
}

\begin{abstract}
Offering feed supplements to grazing dairy cows results in a reduction in grazing time. However, the effect differs depending on the time of day that feeds are offered. To understand the physiological basis for this, associations among circulating factors known to be associated with intake regulation in monogastric species and grazing behavior in the dairy cow were investigated. Seventeen multiparous cows at $28 \pm 5 \mathrm{~d}$ in milk grazed together and consumed $4.4 \mathrm{~kg}$ of dry matter/d of a pelleted concentrate feed supplement, equally split, at the a.m. and p.m. milking. Grazing behavior was recorded over 4 consecutive days in all 17 cows. Blood was sampled from 10 of the 17 cows every $4 \mathrm{~h}$ over a 48 -h period following the grazing behavior measurements; sampling times were staggered by $2 \mathrm{~h}$ to provide a diurnal profile of humoral factors. Grazing profiles illustrated major grazing bouts after the a.m. and p.m. milking; however, the p.m. grazing bout was characterized as the most intensive and time spent grazing was unaffected by supplementation. Associations among proportion of cows grazing and circulating hormones and metabolites differed throughout the day. During the a.m., relationships were consistent with those reported in monogastric species, with ghrelin and nonesterified fatty acids decreasing and insulin increasing with feeding. In comparison, during the major grazing bout predusk, ghrelin concentrations increased until sunset, despite the large proportion of cows grazing, before declining; this is consistent with ghrelin stimulating the predusk grazing bout. Results indicate that humoral factors known to affect hunger and satiety in monogastric animals may also have a potential role in the physiological regulation of diurnal and feeding behavior in ruminants.
\end{abstract}

Key words: grazing behavior, dairy cow, humoral

Received September 25, 2012.

Accepted January 2, 2013.

${ }^{1}$ Corresponding author: angela.sheahan@dairynz.co.nz

\section{INTRODUCTION}

Relatively low DM and ME intakes are primary limitations to productivity in pasture-based dairy systems, resulting in nutrient intakes that are insufficient to match the milk-production potential of the grazing dairy cow (Kolver and Muller, 1998). Supplementary feeds are often offered to grazing cows in an attempt to overcome these limitations (Stockdale, 1999; Bargo et al., 2003). However, total DMI does not increase by the amount of supplement consumed, as cows reduce their pasture DMI when offered supplementary feeds (Bargo et al., 2003; Sheahan et al., 2011). This substitution of supplement for pasture is reflected in changes in dairy cow grazing behavior, with a reported 12-min decrease in grazing time for every $1 \mathrm{~kg}$ of DM supplement consumed (Bargo et al., 2003; Sheahan et al., 2011).

Sheahan et al. (2011) reported that the effect of supplement on grazing behavior was not consistent throughout the day. In cows offered a supplementary feed twice per day, grazing time during the major grazing event following sunrise was reduced, but not in the most intensive grazing event of the day immediately preceding sunset (Gibb et al., 1998). Results indicated that different factors may regulate grazing behavior at these times.

Because of the apparent difference in the grazing behavior response to supplementation, Sheahan et al. (2013) supplemented grazing dairy cows with $3 \mathrm{~kg}$ of pelleted concentrate DM at either the a.m. or p.m. milking, hypothesizing that substitution would be less in the p.m.-supplemented group. Results, however, indicated a similar reduction in time spent grazing throughout the day, regardless of when supplementary feeds were offered. These data did indicate an effect of time of day on the change in grazing behavior in response to feeding, but irrespective of timing of feeding. Supplementary feeds caused a relatively quick reduction in grazing time in the morning, but this effect was delayed in the afternoon; these results are consistent with different factors regulating the onset and cessation of feeding in the major grazing events (i.e., postsunrise 
and presunset). Data also indicated an effect of supplement on grazing behavior beyond the period of supplement consumption and possibly digestion (Sheahan et al., 2013).

The mechanisms that regulate postprandial satiety are still being established and this is particularly true in ruminant animals. It is believed that short-term signals, including gut hormones and neural signals from the gut, liver, and higher brain centers regulate meal initiation and termination (Murphy et al., 2006; Roche et al., 2008a). The gastrointestinal tract is the body's largest endocrine organ (Ahlman and Nilsson, 2001), releasing more than 30 known peptide hormones (Ahlman and Nilsson, 2001; Murphy et al., 2006). Although their role in the regulation of gastrointestinal function is well established, there is increasing evidence that many also influence eating behavior (Badman and Flier, 2005; Murphy et al., 2006).

The majority of research in intake regulation has been undertaken in monogastric species. However, some of these factors are important in intake regulation in ruminant animals (Sugino et al., 2002; Takahashi et al., 2006; Roche et al., 2007, 2008a). For example, a linear decline in plasma ghrelin concentrations was observed $2 \mathrm{~h}$ after dairy cows received a concentrate supplement in the morning (Roche et al., 2007), coincident with the timing of grazing cessation in response to the level of supplementary feeding.

The role and importance of gut-derived peptides in ruminant animals is complicated due to their unique digestive system, in that there is a constant flow of ingesta into the abomasum, as opposed to discrete meals in the monogastric. The objective of this study was to investigate circulating factors known to be associated with intake regulation in monogastric species for a role in the regulation of grazing behavior in the dairy cow.

\section{MATERIALS AND METHODS}

This experiment was conducted at Lye Farm, DairyNZ, Hamilton, New Zealand $\left(37^{\circ} 46^{\prime} \mathrm{S} 175^{\circ} 18^{\prime} \mathrm{E}\right)$ during September 2006, and all procedures were approved by the Ruakura Animal Ethics Committee (Hamilton, New Zealand).

\section{Experimental Design}

The 17 multiparous cows used for this experiment were the control group from a larger study (Roche et al., 2008b). At the start of the experiment, average cow data (mean $\pm \mathrm{SD}$ ) were as follows: calving date $=$ July $17 \pm 5 \mathrm{~d}$, parity $=6 \pm 2 \mathrm{yr}$, preexperimental $\mathrm{BW}=481$ $\pm 61.9 \mathrm{~kg}, \mathrm{BCS}=4.6 \pm 0.38 \mathrm{BCS}$ units on a 10 -point scale (Roche et al., 2004), and milk production $=23.4$ $\pm 3.70 \mathrm{~kg}$ of milk/d, with $1.1 \pm 0.19 \mathrm{~kg}$ of fat $/ \mathrm{d}, 0.8 \pm$ $0.13 \mathrm{~kg}$ of protein $/ \mathrm{d}, 4.6 \pm 0.44 \%$ fat, and $3.4 \pm 0.20 \%$ protein.

\section{Pasture Management and Supplementary Feeds}

Cows were rotationally grazed as one herd for the duration of the experiment, with the exception of when blood sampling occurred: 10 of the 17 cows sampled were kept as a separate group for the 48-h duration of sampling for ease of blood collection. Cows had access to a fresh allocation of pasture twice daily after the a.m. and p.m. milking. Pasture allowance $(>40 \mathrm{~kg}$ of $\mathrm{DM} /$ cow per day) was sufficient to ensure unrestricted DMI (up to approximately $20 \mathrm{~kg}$ of $\mathrm{DM} / \mathrm{d}$ ) of fresh pasture. Water was available ad libitum in each grazing area. Near-infrared spectroscopy confirmed the pasture was of high quality $(\mathrm{CP}=24.3 \pm 2.40 \%$ of $\mathrm{DM}$; NDF $=38.4 \pm 3.02 \%$ of $\mathrm{DM} ; \mathrm{ADF}=20.4 \pm 1.05 \%$ of $\mathrm{DM}$; lipid $=4.1 \pm 0.18 \%$ of $\mathrm{DM}$; $\mathrm{NSC}=16.8 \pm 2.98 \%$ of DM; OM digestibility: $>84.0 \%$ of DM; ME: $>12.5$ $\mathrm{MJ} / \mathrm{kg}$ of DM). A flat rate of $4.4 \mathrm{~kg}$ of $\mathrm{DM}$ pelleted concentrate $(32 \%$ crushed barley, $60 \%$ crushed maize, $2 \%$ wheat middlings, and $6 \%$ molasses; $\mathrm{CP}=14.1 \pm$ $0.16 \%$ of $\mathrm{DM} ; \mathrm{NDF}=16.8 \pm 0.47 \%$ of $\mathrm{DM} ; \mathrm{ADF}=7.7$ $\pm 0.39 \%$ of DM; lipid $=3.5 \pm 0.19 \%$ of $\mathrm{DM}$; NSC $=$ $56.7 \pm 0.62 \%$ of $\mathrm{DM}$ ) was split equally in 2 feeds daily and offered during the a.m. (0640-0800 h) and p.m. (1430-1500 h) milkings.

\section{Animal Measurements}

Grazing Behavior. Grazing behavior was recorded for all 17 cows for 4 consecutive days. Time spent grazing, ruminating (lying and standing), and idle (not grazing or ruminating) was determined by recording each cow's activity at 10-min intervals throughout a 24-h period while the cows were in the paddock (Gary et al., 1970). Grazing was defined as cows in the act of eating. The 24-h observation periods were further divided into 4 time blocks (TB): TB1 $(0010-0600 \mathrm{~h})$, TB2 (0610-1400 h), TB3 (1410-1800 h), and TB4 (1810-0000 h). Sunrise and sunset times were averaged for the $4 \mathrm{~d}$ (0620 and $1810 \mathrm{~h}$, respectively; http://www. timeanddate.com, accessed August 29, 2012).

Jugular Catheters and Blood Sampling. Immediately following grazing behavior measurements (the day before blood sampling), a jugular catheter (14 gauge $\times 19.6 \mathrm{~cm}$; Delmed Inc., New Brunswick, NJ) was inserted under local anesthetic into 10 of the 17 cows. After each blood collection, catheters were flushed with $10 \mathrm{~mL}$ of isotonic saline with $50 \mathrm{IU} / \mathrm{mL}$ of heparin sodium (Multiparin; Fisons Pharmaceuticals, NSW, Australia). Blood was sampled every $4 \mathrm{~h}$ for $48 \mathrm{~h}$, com- 
mencing at $1000 \mathrm{~h}$ and every $4 \mathrm{~h}$ thereafter until 0600 $\mathrm{h}$ the following morning; then, the blood sampling was staggered by $2 \mathrm{~h}$, with collection at $0800 \mathrm{~h}$ and every $4 \mathrm{~h}$ thereafter. The staggered blood sampling was done to minimize disruption to the cow's normal grazing behavior by frequent removal from the paddock while still achieving 2 hourly samples relative to feeding. Cows were returned to their paddock after sampling.

Blood. Two evacuated 10-mL blood tubes (140 IU of sodium heparin and $0.117 \mathrm{~mL}$ of $15 \%$ potassium EDTA) were collected from each cow. Following centrifugation $\left(1,120 \times g\right.$ for 12 min at $\left.4^{\circ} \mathrm{C}\right)$, plasma from the EDTAblood tubes were acidified using $0.1 \mathrm{~N} \mathrm{HCl}$ and treated with phenylmethylsufonyl fluoride for ghrelin analysis (as per kit instructions; Millipore Corp., Billerica, MA) and stored at $-20^{\circ} \mathrm{C}$ until analysis. Analyses for NEFA (colorimetric method) and glucose (hexokinase method) were performed on a Hitachi 717 analyzer (Roche, Basel, Switzerland) at $30^{\circ} \mathrm{C}$ by Alpha Scientific Ltd. (Hamilton, New Zealand). The inter- and intra assay coefficients of variation were $<2 \%$. Growth hormone (GH; Downing et al., 1995), IGF-1 (Gluckman et al., 1983), insulin (Hales and Randle, 1963), and leptin (Blache et al., 2000) were measured in duplicate by double-antibody RIA with inter- and intraassay coefficients of variation $<6 \%$. Plasma ghrelin concentrations were measured using the Millipore active ghrelin RIA kit (GHRA-88HK; Millipore Corp.). The inter- and intraassay coefficients of variation were 7 and $6 \%$, respectively. Plasma glucagon was measured using the glucagon RIA kit (XL-85K; Millipore Corp.). The kit was specific for pancreatic glucagon and cross-reaction with oxyntomodulin (gut glucagon) was $<0.1 \%$. The intraassay coefficient of variation was $5 \%$. Plasma glucagon-like peptide 1 (GLP-1) was measured using an RIA kit (GLP1T-36HK; Millipore Corp.), utilizing an antibody that recognizes all forms of GLP-1. The intraassay coefficient of variation was $9 \%$.

\section{Statistical Analysis}

A paired 2-tailed $t$-test was performed to investigate diurnal variation in circulating humoral factors over a 24-h period. Due to the uncertain distribution of the percentage time associated with behavior observations and the repeated nature of the data per cow, a bootstrap-based regression analysis with clustered regression was used to investigate the nature and significance of the behavior and blood metabolite level association. The bootstrap regression implementation served to help isolate the regression coefficient confidence intervals and for this guidelines in Efron and Tibshirani (1993) were used. The use of clustering (on cow) allowed the relaxation of the assumption of observation independence (Hamilton, 2009), by admitting common cow-based variance estimates and, thus, more realistically allowing the isolation of standard errors of the regression estimates.

\section{RESULTS}

The diurnal grazing profile (Figure 1a) illustrates that grazing was mainly confined to the hours between sunrise and sunset. Within this period, cows had major grazing bouts after the a.m. and p.m. milking, with intermittent shorter grazing events. Grazing during the hours of darkness (between sunset and sunrise) was minimal, particularly between 0200 and $0530 \mathrm{~h}$.

Although fresh pasture was allocated after each milking, results indicate that grazing profiles were different; this was particularly evident during the first 4 $\mathrm{h}$ after the a.m. and p.m. milkings, which represent when the majority of grazing occurred. Following the a.m. milking, $94 \%$ of cows grazed for $1 \mathrm{~h}$; from $1 \mathrm{~h}$, grazing gradually declined to $35 \% 4 \mathrm{~h}$ after grazing commenced. In comparison, grazing behavior following the p.m. milking differed in that $87 \%$ cows continued to graze for $3 \mathrm{~h}$ until sunset $(1800 \mathrm{~h})$, at which point grazing declined to $9 \%$ by $4 \mathrm{~h}$ postmilking.

The diurnal rumination profile (Figure 1b) illustrates that, although rumination occurred during the day, the majority occurred between sunset and sunrise (i.e., during darkness). The profile for the diurnal idle behavior (Figure 1c) was similar to that of the rumination profile (i.e., the majority of idle behavior during the hours of darkness), with the exception of the period just before sunset, when the proportion of idle cows increased.

Diurnal concentrations of humoral factors are presented in Figure 2a to 2i. Results indicate that the main changes in concentration occurred during or after periods of grazing. Ghrelin concentration decreased soon after grazing commenced in the a.m., but increased ( $P$ $<0.001$ ) during the p.m. grazing bout until sunset, thereafter declining to its lowest measured concentration at $2000 \mathrm{~h}$. Insulin concentrations increased after grazing in both the a.m. and the p.m., but the level and duration was greater in the p.m. Glucose concentrations remained constant during the a.m. grazing bout, but decreased linearly $(P<0.01)$ during the p.m. grazing bout, before recovering by $2200 \mathrm{~h}$. Nonesterified FA concentrations were highest before the a.m. grazing bout $(0600 \mathrm{~h})$, decreased during the a.m. grazing bout to a level that was maintained until $0000 \mathrm{~h}$, before rising to the predawn peak. During both the a.m. and p.m. grazing bouts, blood GH concentrations decreased; however, the period of decline was longer during the p.m. Concentrations of leptin gradually increased during the day, reaching maximum concen- 
a)

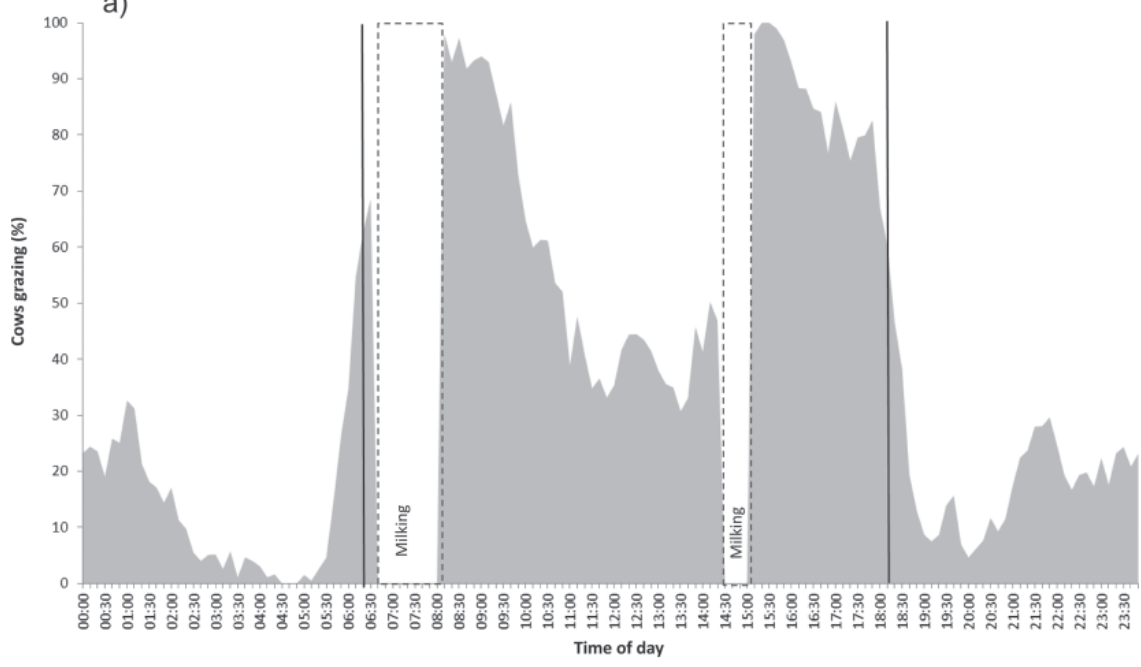

b)

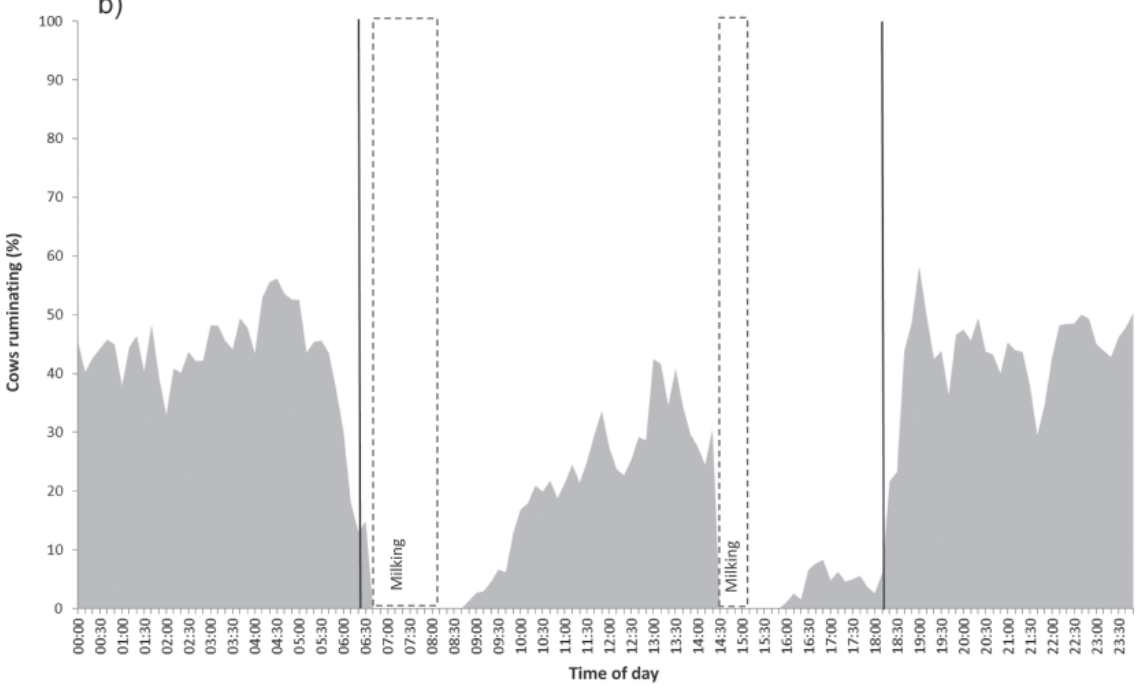

c)

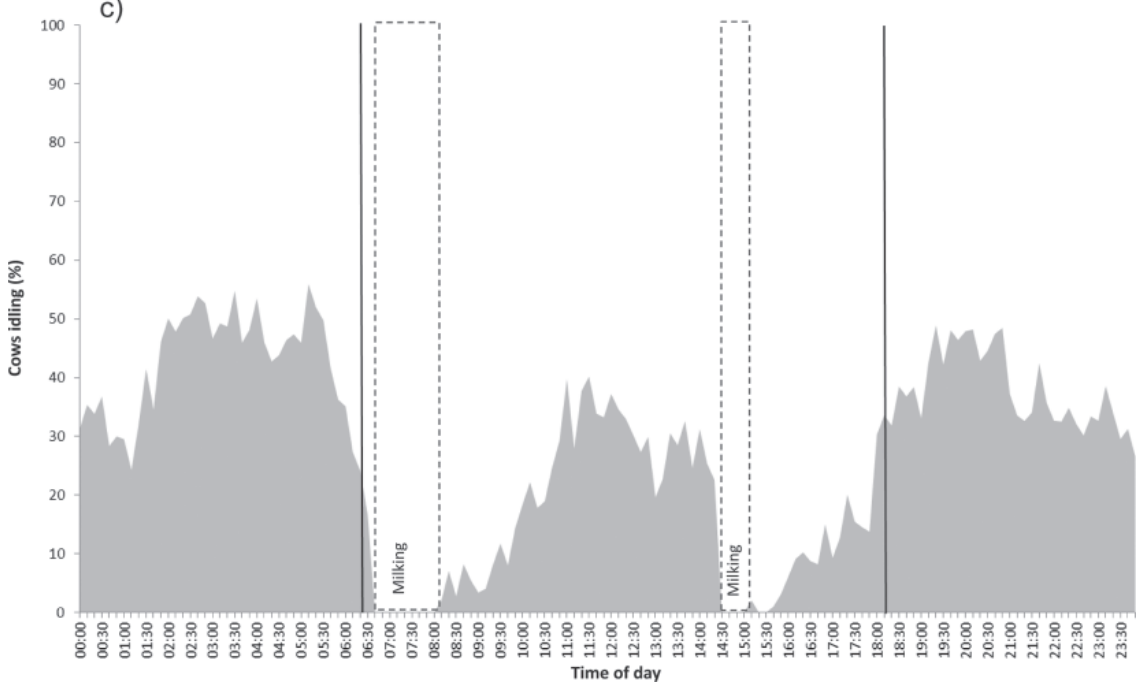

Figure 1. Diurnal profiles of percentage of cows (a) grazing, (b) ruminating, and (c) idling for 17 dairy cows offered $4.4 \mathrm{~kg}$ of DM/d of a concentrate supplementary feed in equal portions at a.m. and p.m. milkings. Vertical solid lines represent sunrise $(0620 \mathrm{~h})$ and sunset $(1810 \mathrm{~h})$. Dashed lines represent a.m. and p.m. milking. 
tration at $2200 \mathrm{~h}$, and declining thereafter. Glucagonlike peptide 1 concentrations increased during grazing activity and in particular during TB3, declining during TB4, when grazing activity was low. Glucagon concentrations remained fairly constant throughout the day, before increasing in the evening (1800 and $2000 \mathrm{~h}$ ). By $2200 \mathrm{~h}$, glucagon had returned to concentrations similar to those recorded at other times during the day. Insulin-like growth factor 1 plasma concentrations did not change throughout the day.

The behavior and blood metabolite associations were as follows: during TB1, concentrations of ghrelin [observed coefficient $(\mathbf{O C})=-0.02, \mathrm{R}^{2}=0.22, P<$ $0.001]$ and GLP-1 $\left(\mathrm{OC}=-0.12, \mathrm{R}^{2}=0.18, P<0.01\right)$ increased with decreased grazing activity (i.e., negative association), whereas insulin $\left(\mathrm{OC}=1.41, \mathrm{R}^{2}=\right.$ $0.13, P<0.05)$ and glucose $\left(\mathrm{OC}=11.4, \mathrm{R}^{2}=0.29\right.$, $P<0.001)$ decreased (i.e., positive association). During TB2, concentrations of ghrelin $\left(\mathrm{OC}=0.08, \mathrm{R}^{2}=\right.$ 0.31, $P<0.001)$, insulin $\left(\mathrm{OC}=1.36, \mathrm{R}^{2}=0.05, P=\right.$ $0.05)$, glucose $\left(\mathrm{OC}=24, \mathrm{R}^{2}=0.15, P<0.01\right)$, and NEFA $\left(\mathrm{OC}=84.4, \mathrm{R}^{2}=0.06, P<0.01\right)$ decreased as the proportion of cows grazing declined (i.e., positive association), whereas GH $\left(\mathrm{OC}=-10.5, \mathrm{R}^{2}=0.10, P\right.$ $<0.05)$, glucagon $\left(\mathrm{OC}=-0.17, \mathrm{R}^{2}=0.05, P<0.01\right)$, and leptin $\left(\mathrm{OC}=-26.9, \mathrm{R}^{2}=0.07, P<0.05\right)$ increased (i.e., negative association). During TB3, concentrations of ghrelin $\left(\mathrm{OC}=-0.02, \mathrm{R}^{2}=0.53, P<0.001\right)$, insulin $\left(\mathrm{OC}=-0.44, \mathrm{R}^{2}=0.57, P<0.001\right)$, and GLP-1 (OC $\left.=-0.04, \mathrm{R}^{2}=0.30, P<0.01\right)$ increased with decreases in the proportion of cows grazing (i.e., negative association), whereas $\mathrm{GH}\left(\mathrm{OC}=1.88, \mathrm{R}^{2}=0.26, P<0.001\right)$, glucose $\left(\mathrm{OC}=3.07, \mathrm{R}^{2}=0.40, P<0.001\right)$, and NEFA $\left(\mathrm{OC}=30.1, \mathrm{R}^{2}=0.17, P<0.01\right)$ decreased (i.e., positive association). During TB4, glucose $(\mathrm{OC}=-0.73$, $\left.\mathrm{R}^{2}=0.12, P<0.001\right)$, and NEFA $\left(\mathrm{OC}=-13.6, \mathrm{R}^{2}=\right.$ $0.11, P<0.05)$ concentrations were negatively associated with the proportion of cows grazing, whereas the association between circulating GLP-1 $\left(\mathrm{OC}=0.01, \mathrm{R}^{2}\right.$ $=0.24, P<0.01)$ concentration and grazing behavior was positive.

\section{DISCUSSION}

The experimental objective was to investigate associations among diurnal patterns of grazing behavior and humoral factors reported to regulate intake in nonruminant animals. Data indicate that major periods of grazing occurred after the a.m. and p.m. milking, with little grazing activity during the hours of darkness. Diurnal changes in humoral factors and associations between grazing behavior and humoral factors are consistent with a role for these factors in regulating grazing behavior.
The presented grazing profile is consistent with previous reports that grazing dairy cows exhibit diurnal grazing behavior (Hafez, 1969; Krysl and Hess, 1993; Sheahan et al., 2011) with crepuscular tendencies (Gibb et al., 1998; Taweel et al., 2004; Sheahan et al., 2011). Although cows were offered equal amounts of a concentrate supplement while being milked and equal access to fresh pasture after both the a.m. and p.m. milking (i.e., had the same opportunity to eat following both a.m. and p.m. milking), data indicate that grazing was more intensive in the $4 \mathrm{~h}$ after milking in the p.m. compared with the a.m. These data are consistent with the hypothesis that different factors regulate grazing behavior in the a.m. compared with the p.m. (Sheahan et al., 2011).

Associations between grazing behavior during TB1, the period of lowest activity, and circulating humoral factors are similar to those reported in the literature. For example, the decrease in insulin concentration and increase in NEFA concentration during TB1 is consistent with a fasted state imposed by darkness, with a reduction in circulating insulin concentration facilitating lipid secretion from adipose stores into blood (Lafontan et al., 2009). The increase in plasma ghrelin concentrations is consistent with the reported increase when ruminant (Wertz-Lutz et al., 2006; Roche et al., 2006, 2007) and monogastric species (Tschöp et al., 2000; Lee et al., 2002) are in a fasted or preprandial state.

Cow energy status changed from a state of tissue catabolism to anabolism during TB2, as indicated by the sharp decrease in circulating NEFA concentration (Lafontan et al., 2009) shortly after grazing commenced in the a.m. The decreasing plasma ghrelin concentration and the proportion of cows grazing during TB2 is consistent with the reported decrease in ghrelin in response to a meal in both ruminant (Sugino et al., 2002; Wertz-Lutz et al., 2006; Roche et al., 2007) and monogastric (Cummings et al., 2001) species. The elevated insulin concentration $2 \mathrm{~h}$ after the initiation of a meal (Manns and Boda, 1967; Brockman, 1978; Perboni et al., 2009) and the decrease in GH concentrations with the proportion of cows spent grazing is further evidence of a return to positive energy balance (Hove and Blom, 1973; Lafontan et al., 2009). These data indicate that, during TB2, the temporal patterns of plasma ghrelin, insulin, NEFA, and GH in a grazing dairy cow are similar to those reported in monogastric species.

The increase in ghrelin concentrations during TB3 despite intensive grazing for $3 \mathrm{~h}$ is unique and contrary to publications stating that ghrelin concentration decreases after meal initiation (Cummings et al., 2001; Roche et al., 2007). Interestingly, the increase in ghrelin concentration was also during a period of low blood NEFA concentration and increasing blood insulin con- 
a)

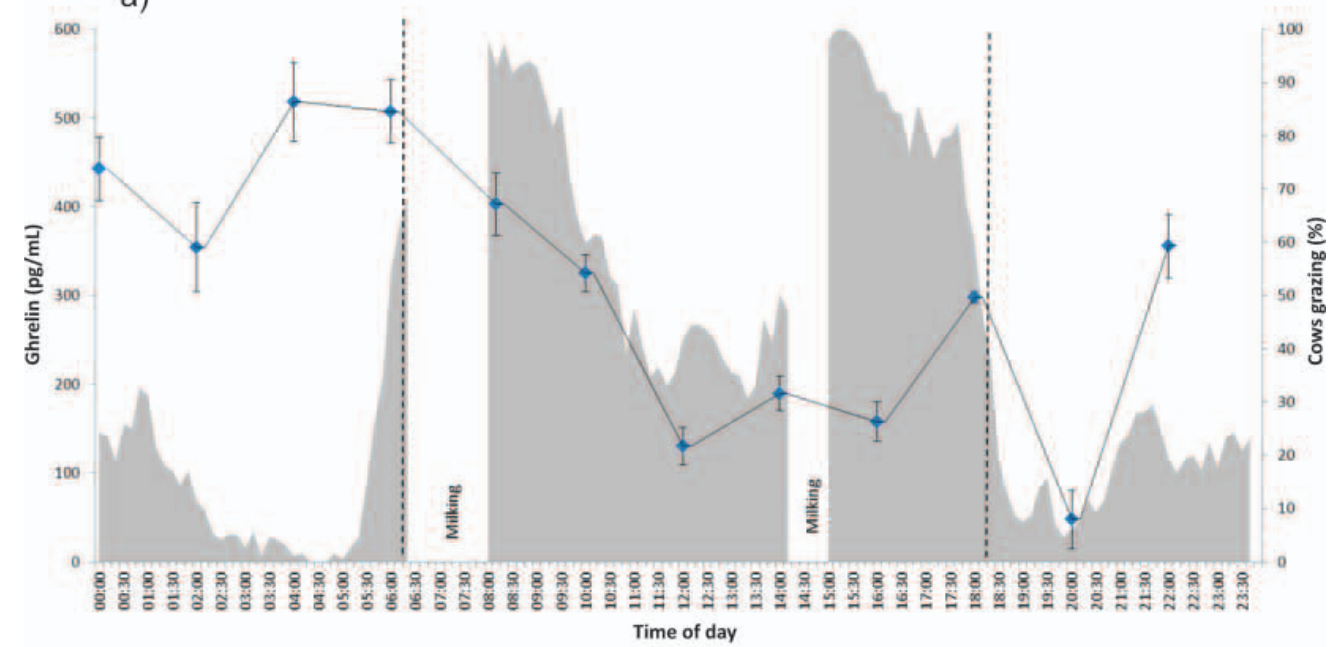

b)

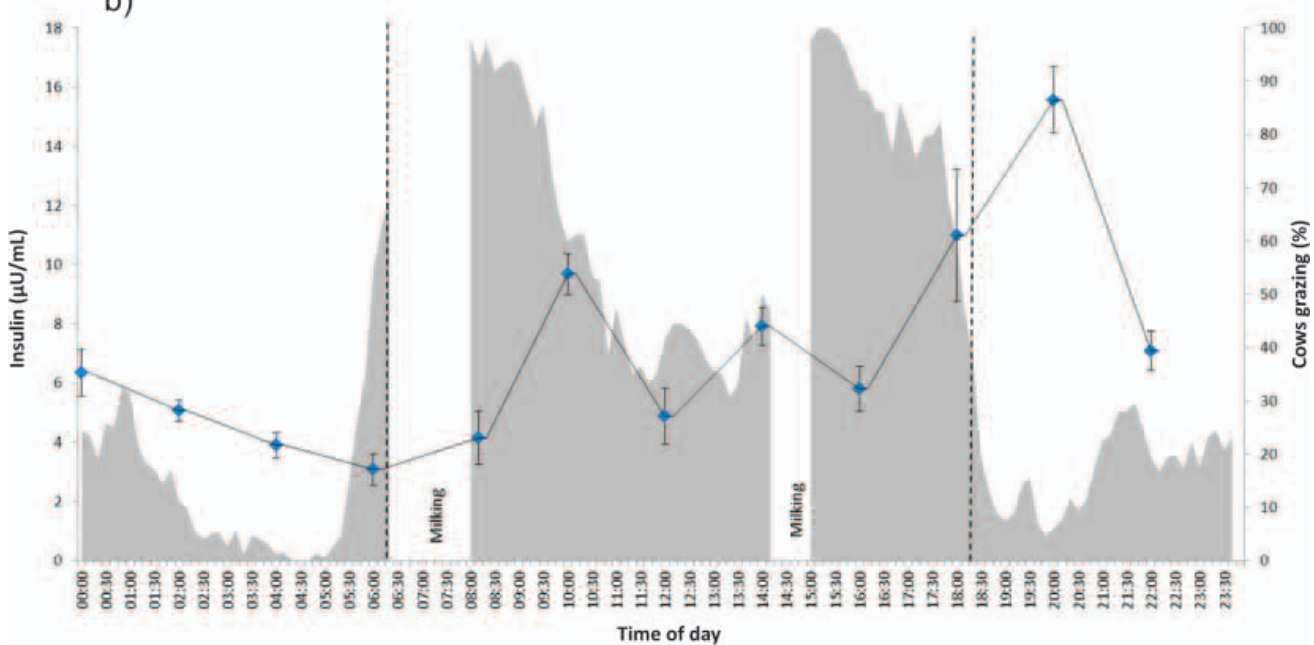

c)

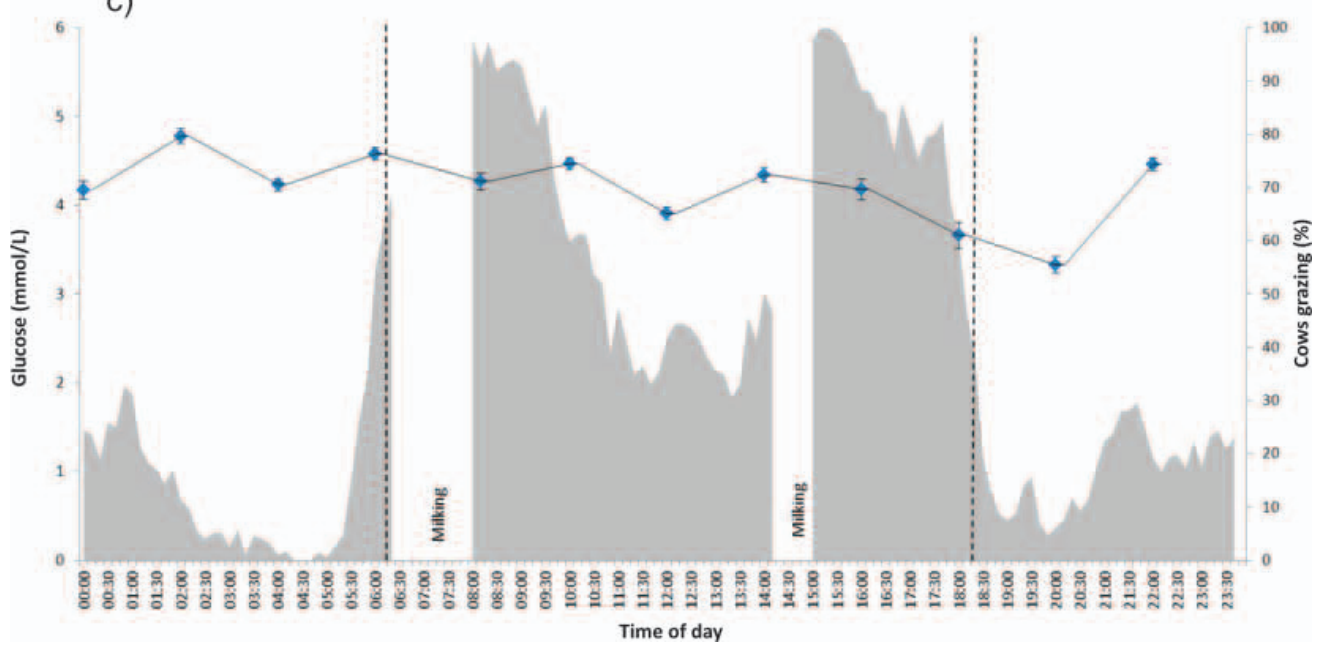

Figure 2. Diurnal profiles of grazing behavior for 17 cows (proportion of cows grazing; shaded) and averaged circulating humoral factors considered to have a regulatory role in intake regulation: (a) ghrelin, (b) insulin, (c) glucose, (d) NEFA, (e) growth hormone, (f) leptin, (g) glucagon-like peptide 1 (GLP-1), (h) glucagon, and (i) IGF-1 for 10 of the 17 cows offered $4.4 \mathrm{~kg} / \mathrm{d}$ of a concentrate supplementary feed in equal portions at a.m. and p.m. milkings. Vertical dashed lines represent sunrise $(0620 \mathrm{~h})$ and sunset $(1810 \mathrm{~h})$. Standard error of the mean bars are included. Color version available in the online PDF. 
d)

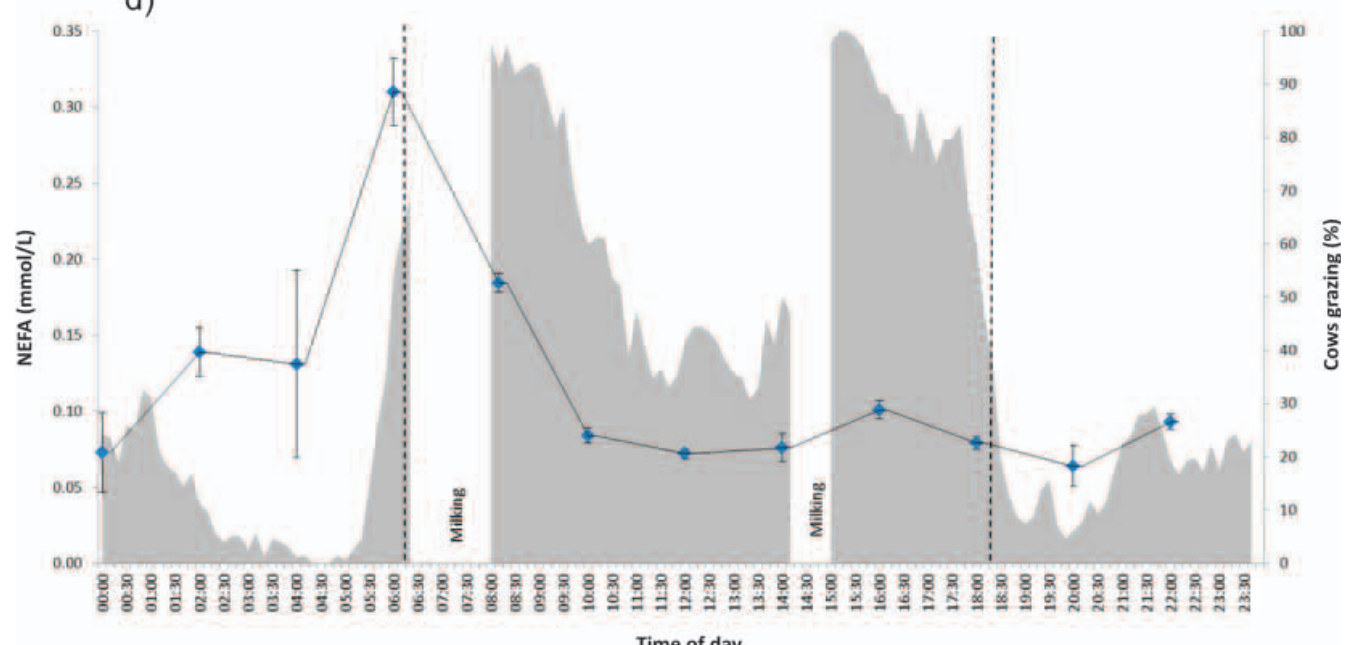

e)

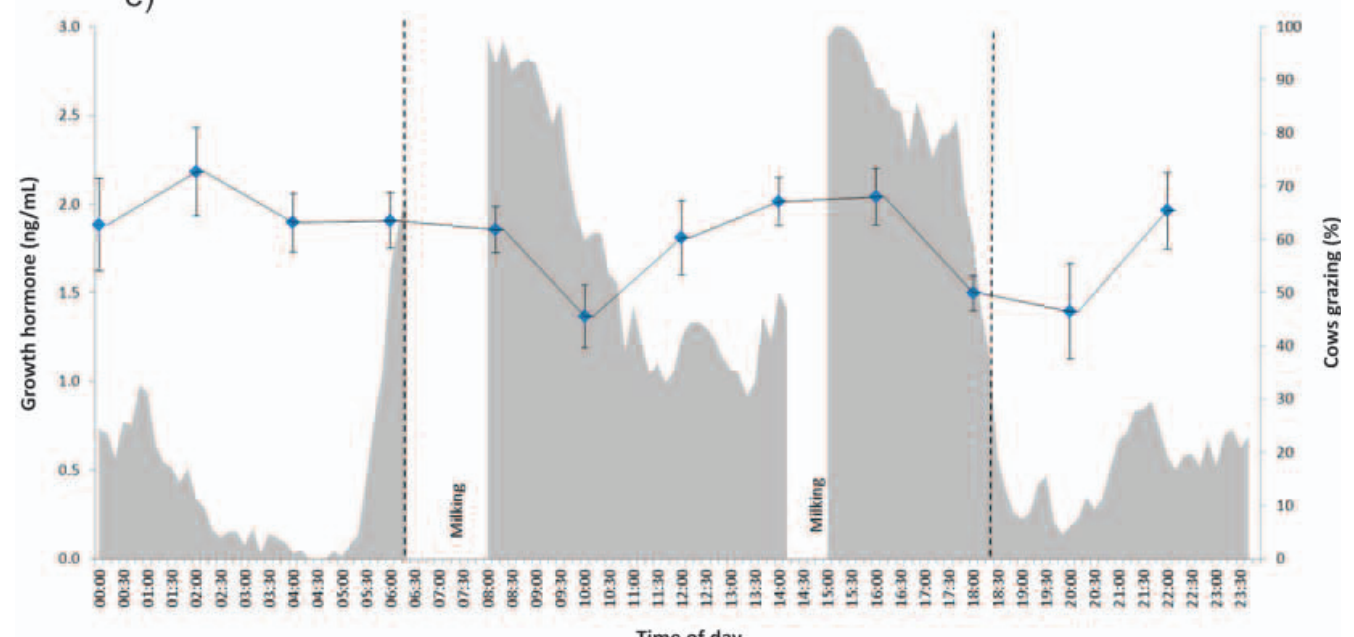

f)

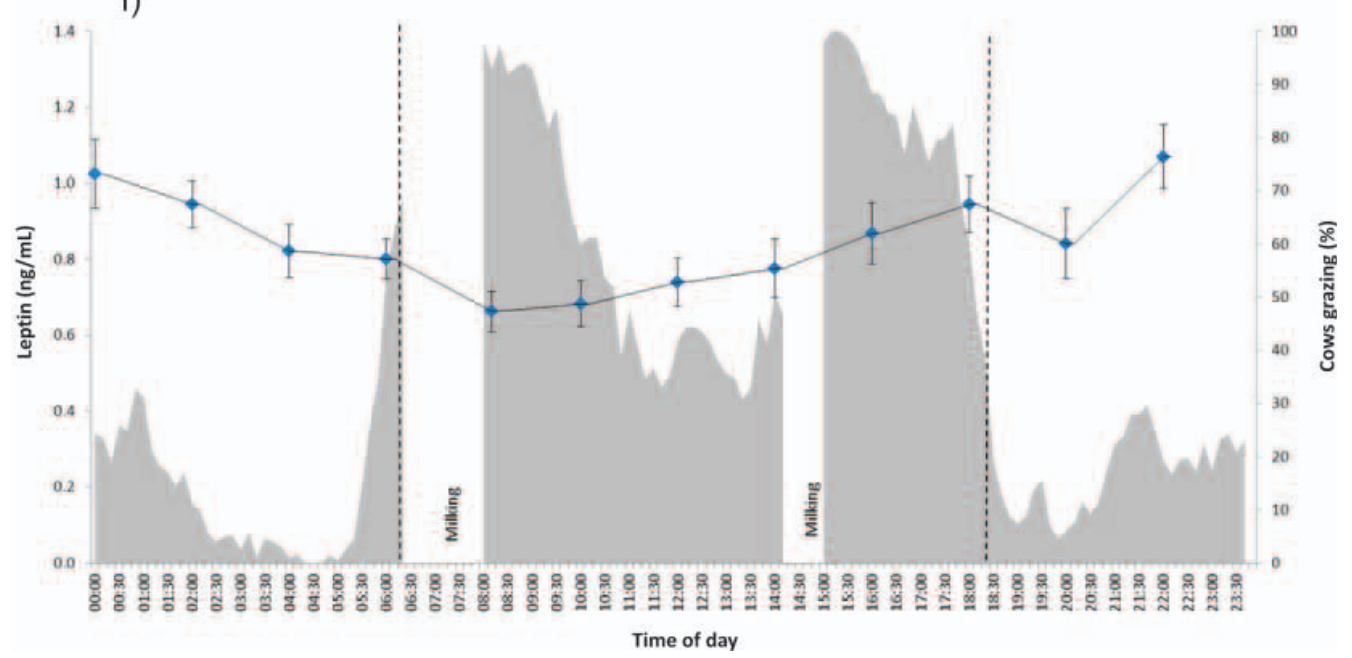

Figure 2 (Continued). Diurnal profiles of grazing behavior for 17 cows (proportion of cows grazing; shaded) and averaged circulating humoral factors considered to have a regulatory role in intake regulation: (a) ghrelin, (b) insulin, (c) glucose, (d) NEFA, (e) growth hormone, (f) leptin, (g) glucagon-like peptide 1 (GLP-1), (h) glucagon, and (i) IGF-1 for 10 of the 17 cows offered $4.4 \mathrm{~kg} / \mathrm{d}$ of a concentrate supplementary feed in equal portions at a.m. and p.m. milkings. Vertical dashed lines represent sunrise $(0620 \mathrm{~h})$ and sunset (1810 h). Standard error of the mean bars are included. Color version available in the online PDF. 
g)

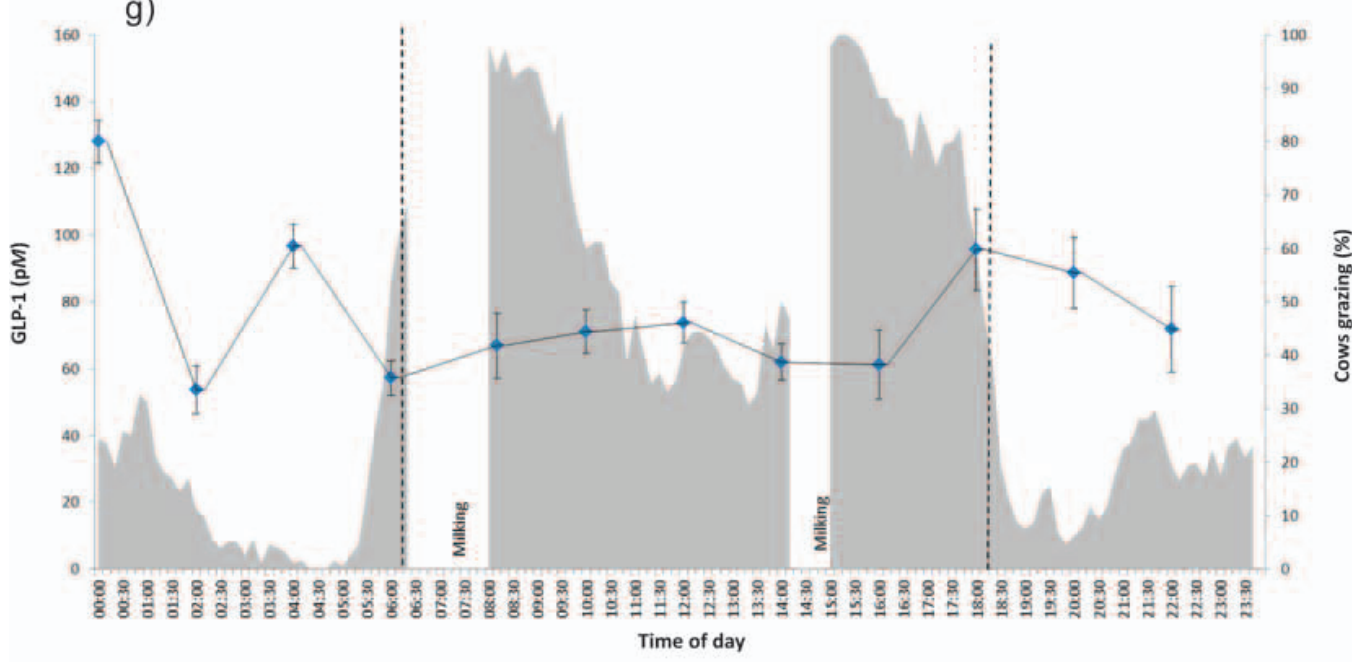

h)

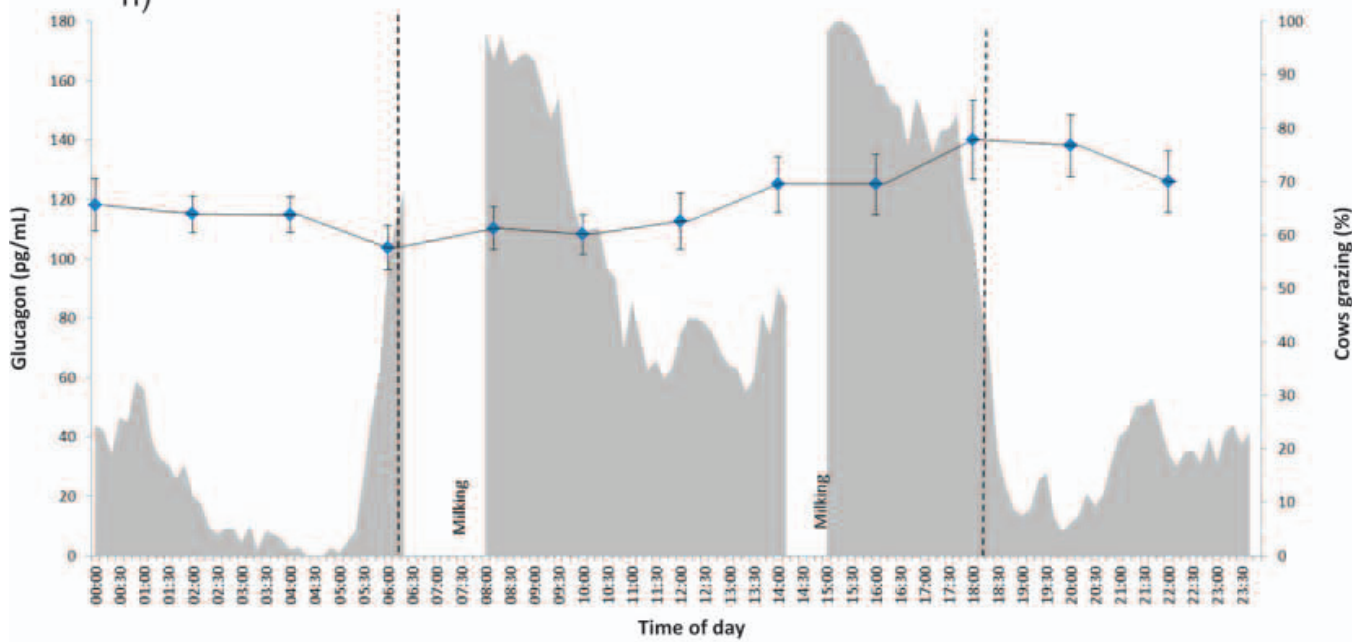

i)

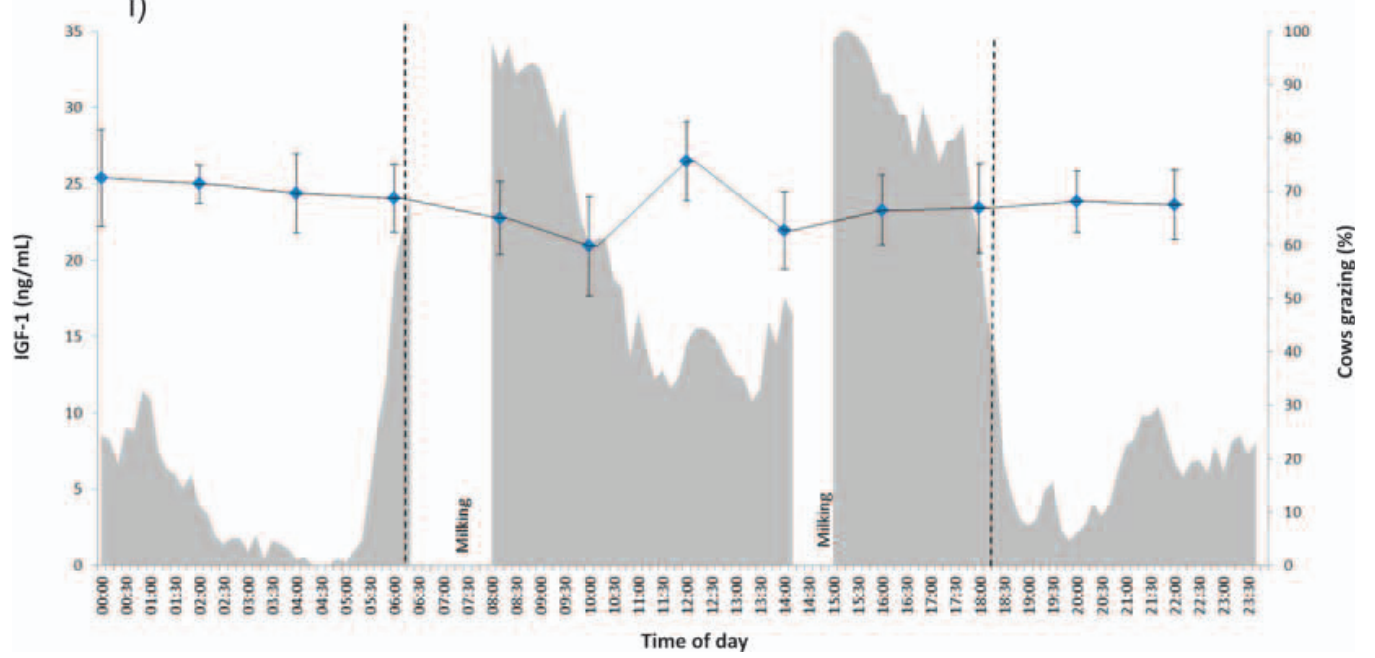

Figure 2 (Continued). Diurnal profiles of grazing behavior for 17 cows (proportion of cows grazing; shaded) and averaged circulating humoral factors considered to have a regulatory role in intake regulation: (a) ghrelin, (b) insulin, (c) glucose, (d) NEFA, (e) growth hormone, (f) leptin, (g) glucagon-like peptide 1 (GLP-1), (h) glucagon, and (i) IGF-1 for 10 of the 17 cows offered $4.4 \mathrm{~kg} / \mathrm{d}$ of a concentrate supplementary feed in equal portions at a.m. and p.m. milkings. Vertical dashed lines represent sunrise $(0620 \mathrm{~h})$ and sunset (1810 h). Standard error of the mean bars are included. Color version available in the online PDF. 
centrations; these associations are unique in themselves, as insulin is a potent suppressor of ghrelin secretion (Flanagan et al., 2003). Roche et al. (2008c) reported an increase in ghrelin in grazing dairy cows following the insulin-stimulated decline in NEFA concentration resulting from an intravenous glucose tolerance test. The increase in ghrelin concentration, therefore, could be related to an evolutionary physiological awareness of impending darkness, overriding ghrelin-regulating factors associated with meal consumption to ensure that cows continue to graze until darkness.

This phenomenon has also been reported in darkphase feeders. Using mice, Murakami et al. (2002) measured an increase in plasma ghrelin concentration before the onset of the dark phase and a second increase during the last $3 \mathrm{~h}$ of the dark phase, coincident with gastric contents increasing by $50 \%$. Bodosi et al. (2004) also reported an increase in ghrelin before the dark phase in rats; however, they did not report the second peak at the end of the dark phase. This inconsistency may be due to the less-frequent blood sampling regimen (every $4 \mathrm{~h}$ ) of Bodosi et al. (2004), thus missing the occurrence of the second peak. Although this area requires further investigation, current data indicate that the diurnal and possibly, crepuscular feeding behavior of both light- and dark-phase feeders are associated with elevated ghrelin concentrations both before and toward the end of the feeding period, ensuring that diurnal animals maximize use of their preferred feeding periods. This hypothesis is supported by Drazen et al. (2006), who reported a delay in the postprandial decline in circulating ghrelin when rats were habituated to consuming their daily allowance in a 4 -h period, suggesting that factors regulating feeding behavior can be influenced by environment.

The increase in GLP-1 concentration during TB3 may also contribute to the delay in the postprandial decline in ghrelin concentration after a meal. Faulkner and Pollock (1991) reported that the postprandial decline in ghrelin concentration was suppressed in sheep infused with GLP-1. Results from the current study indicate that the suppression of the postprandial decline in circulating ghrelin is key in facilitating the greater grazing intensity reported preceding darkness (Gibb et al., 1998; Sheahan et al., 2011) and that this feature may, itself, be regulated by humoral factors also implicated in intake regulation.

The increase in ghrelin concentrations during TB4 to levels maintained until sunrise while feeding activity is minimal is probably associated with the reported nocturnal rise in ghrelin concentration associated with sleep in monogastric species (Cummings et al., 2001; Dzaja et al., 2004). These data and the associations identified in TB4 indicate that increased concentra- tions of ghrelin do not necessarily reflect a physiological drive to eat and that single-sample points should not be interpreted as representative of hunger. If ghrelin concentrations are to be used as an indicator of hunger, frequent blood sampling must be undertaken.

\section{CONCLUSIONS}

Diurnal profiles of humoral factors known to be associated with intake regulation in monogastric species appear to have an intake regulatory role in the grazing dairy cow. What is most interesting is the nonconventional relationship between ghrelin and grazing behavior and ghrelin and insulin presunset. The data indicate a role for ghrelin in the increased presunset feeding activity in diurnal and, possibly, crepuscular animals; however, other factors may promote or temper ghrelin's role in feeding behavior.

\section{ACKNOWLEDGMENTS}

The authors acknowledge assistance and contributions of Jane Kay (DairyNZ, Hamilton, New Zealand), DairyNZ Lye Farm staff, and the DairyNZ technical team. This work was funded by New Zealand dairy farmers through DairyNZ Inc.

\section{REFERENCES}

Ahlman, H., and O. Nilsson. 2001. The gut as the largest endocrine organ in the body. Ann. Oncol. 12:S63-S68.

Badman, M. K., and J. S. Flier. 2005. The gut and energy balance: Visceral allies in the obesity wars. Science 307:1909-1914.

Bargo, F., L. D. Muller, E. S. Kolver, and J. E. Delahoy. 2003. Invited review: Production and digestion of supplemented dairy cows on pasture. J. Dairy Sci. 86:1-42.

Blache, D., R. L. Tellam, L. M. Chagas, M. A. Blackberry, P. E. Vercoe, and G. B. Martin. 2000. Level of nutrition affects leptin concentrations in plasma and cerebrospinal fluid in sheep. J. Endocrinol. 165:625-637.

Bodosi, B., J. Gardi, I. Hajdu, E. Szentirmai, F. Obal Jr., and J. M. Krueger. 2004. Rhythms of ghrelin, leptin, and sleep in rats: Effects of the normal diurnal cycle, restricted feeding, and sleep deprivation. Am. J. Physiol. Regul. Integr. Comp. Physiol. 287:R1071-R1079.

Brockman, R. P. 1978. Roles of glucagon and insulin in the regulation of metabolism in ruminants - A review. Can. Vet. J. 19:55-62.

Cummings, D. E., J. Q. Purnell, R. S. Frayo, K. Schmidova, B. E. Wisse, and D. S. Weigle. 2001. A preprandial rise in plasma ghrelin levels suggests a role in meal initiation in humans. Diabetes 50:1714-1719.

Downing, J. A., J. Joss, P. Connell, and R. J. Scaramuzzi. 1995. Ovulation rate and the concentrations of gonadotrophic and metabolic hormones in ewes fed lupin grain. J. Reprod. Fertil. 103:137-145.

Drazen, D. L., T. P. Vahl, D. A. D'Alessio, R. J. Seeley, and S. C. Woods. 2006. Effects of a fixed meal pattern on ghrelin secretion: Evidence for a learned response independent of nutrient status. Endocrinology 147:23-30.

Dzaja, A., M. A. Dalal, H. Himmerich, M. Uhr, T. Pollmächer, and A. Schuld. 2004. Sleep enhances nocturnal plasma ghrelin levels in healthy subjects. Am. J. Physiol. Endocrinol. Metab. 286:E963E967. 
Efron, B., and R. J. Tibshirani. 1993. Standard errors and estimated standard errors and the bootstrap estimate of standard errors. Pages 35-36 in An Introduction to the Bootstrap. Chapman and Hall, New York, NY.

Faulkner, A., and H. T. Pollock. 1991. Effects of truncated glucagonlike peptide-1 on the responses of starved sheep to glucose. J. Endocrinol. 129:55-58.

Flanagan, D. E., M. L. Evans, T. P. Monsod, F. Rife, R. A. Heptulla, W. V. Tamborlane, and R. S. Sherwin. 2003. The influence of insulin on circulating ghrelin. Am. J. Physiol. Endocrinol. Metab. 284:E313-E316.

Gary, L. A., G. W. Sherritt, and E. B. Hale. 1970. Behavior of Charolais cattle on pasture. J. Anim. Sci. 30:203-206.

Gibb, M. J., C. A. Huckle, and R. Nuthall. 1998. Effect of time of day on grazing behaviour by lactating dairy cows. Grass Forage Sci. 53:41-46.

Gluckman, P. D., J. J. Johnson-Barrett, J. H. Butler, B. W. Edgar and T. R. Gunn. 1983. Studies of insulin-like growth factor-I and -II by specific radioligand assays in umbilical cord blood. Horumon To Rinsho 19:405-413.

Hafez, E. S. E. 1969. The Behavior of Domestic Animals. The Williams and Wilkins Co., Baltimore, MD.

Hales, C. N., and P. J. Randle. 1963. Immunoassay of insulin with insulin-antibody precipitate. Biochem. J. 88:137-146.

Hamilton, L. C. 2009. Robust estimates of variance. Pages 273-276 in Statistics with Stata. Version 10. Brooks and Cole, Cengage Learning, Belmont, CA.

Hove, K., and A. K. Blom. 1973. Plasma insulin and growth hormone in dairy cows; diurnal variation and relation to food intake and plasma sugar and acetoacetate levels. Acta Endocrinol. (Copenh.) 73:289-303.

Kolver, E. S., and L. D. Muller. 1998. Performance and nutrient intake of high producing Holstein cows consuming pasture or a tota mixed ration. J. Dairy Sci. 81:1403-1411.

Krysl, L. J., and B. W. Hess. 1993. Influence of supplementation on behavior of grazing cattle. J. Anim. Sci. 71:2546-2555.

Lafontan, M., C. Sengenes, C. Moro, J. Galitzky, and M. Berlan. 2009. Natriuretic peptides and other lipolytic peptides involved in the control of lipid mobilization. Pages 133-161 in Peptides in Energy Balance and Obesity. G. Frühbeck, ed. CAB Int., Oxfordshire, UK.

Lee, H.-M., G. Wang, E. W. Englander, M. Kojima, and G. H. Greeley Jr. 2002. Ghrelin, a new gastrointestinal endocrine peptide that stimulates insulin secretion: Enteric distribution, ontogeny, influence of endocrine, and dietary manipulations. Endocrinology 143:185-190.

Manns, J. G., and J. M. Boda. 1967. Insulin release by acetate, propionate, butyrate and glucose in lambs and adult sheep. Am. J. Physiol. 212:747-755.

Murakami, N., T. Hayashida, T. Kuroiwa, K. Nakahara, T. Ida, M. S. Mondal, M. Nakazato, M. Kojima, and K. Kangawa. 2002. Role for central ghrelin in food intake and secretion profile of stomach ghrelin in rats. J. Endocrinol. 174:283-288.

Murphy, K. G., W. S. Dhillo, and S. R. Bloom. 2006. Gut peptides in the regulation of food intake and energy homeostasis. Endocr. Rev. 27:719-727.
Perboni, S., N. Ueno, G. Mantovani, and A. Inui. 2009. Anorexigenic peptides. Pages 33-60 in Peptides in Energy Balance and Obesity. G. Frühbeck, ed. CAB Int., Oxfordshire, UK

Roche, J. R., D. Blache, D. R. Miller, J. K. Kay, A. J. Sheahan, and D. W. Miller. 2008a. Neuroendocrine and physiological regulation of intake in domesticated ruminants: A review. Nutr. Res. Rev. $21: 207-234$.

Roche, J. R., P. G. Dillon, C. R. Stockdale, L. H. Baumgard, and M. J. VanBaale. 2004. Relationships among international body condition scoring systems. J. Dairy Sci. 87:3076-3079.

Roche, J. R., A. J. Sheahan, L. M. Chagas, and D. P. Berry. 2006 Short communication: Genetic selection for milk production increases plasma ghrelin in dairy cows. J. Dairy Sci. 89:3471-3475.

Roche, J. R., A. J. Sheahan, L. M. Chagas, and D. P. Berry. 2007. Concentrate supplementation reduces postprandial plasma ghrelin in grazing dairy cows: A possible neuroendocrine basis for reduced pasture intake in supplemented cows. J. Dairy Sci. 90:1354-1363.

Roche, J. R., A. J. Sheahan, L. M. Chagas, D. Blache, D. P. Berry, and J. K. Kay. 2008b. Long-term infusions of ghrelin and obestatin in early lactation dairy cows. J. Dairy Sci. 91:4728-4740.

Roche, J. R., A. J. Sheahan, L. M. Chagas, and R. C. Boston. 2008c Short communication: Change in plasma ghrelin in dairy cows following an intravenous glucose challenge. J. Dairy Sci. 91:10051010 .

Sheahan, A. J., S. J. Gibbs, and J. R. Roche. 2013. Timing of supplementation alters grazing behavior and milk production response in dairy cows. J. Dairy Sci. 96:477-483.

Sheahan, A. J., E. S. Kolver, and J. R. Roche. 2011. Genetic strain and diet effects on grazing behavior, pasture intake, and milk production. J. Dairy Sci. 94:3583-3591.

Stockdale, C. R. 1999. The nutritive characteristics of herbage consumed by grazing dairy cows affect milk yield response obtained from concentrate supplementation. Aust. J. Agric. Res. 39:379 387.

Sugino, T., J. Yamaura, M. Yamagishi, A. Ogura, R. Hayashi, Y. Kurose, M. Kojima, K. Kangawa, Y. Hasegawa, and Y. Terashima. 2002. A transient surge of ghrelin secretion before feeding is modified by different feeding regimens in sheep. Biochem. Biophys. Res. Commun. 298:785-788

Takahashi, H., Y. Kurose, S. Kobayashi, T. Sugino, M. Kojima, K. Kangawa, Y. Hasegawa, and Y. Terashima. 2006. Ghrelin enhances glucose-induced insulin secretion in scheduled meal-fed sheep J. Endocrinol. 189:67-75.

Taweel, H. Z., B. M. Tas, J. Dijkstra, and S. Tamminga. 2004. Intake regulation and grazing behavior of dairy cows under continuous stocking. J. Dairy Sci. 87:3417-3427.

Tschöp, M., D. L. Smiley, and M. L. Heiman. 2000. Ghrelin induces adiposity in rodents. Nature 407:908-913.

Wertz-Lutz, A. E., T. J. Knight, R. H. Pritchard, J. A. Daniel, J. A. Clapper, A. J. Smart, A. Trenkle, and D. C. Beitz. 2006. Circulating ghrelin concentrations fluctuate relative to nutritional status and influence feeding behavior in cattle. J. Anim. Sci. 84:32853300 